\title{
Brazilian Portuguese version of the CORE-OM: cross-cultural adaptation of an instrument to assess the efficacy and effectiveness of psychotherapy
}

\author{
Adaptação transcultural para o português brasileiro do instrumento CORE-OM: \\ uma escala para avaliar a eficácia e a efetividade da psicoterapia
} Márcia Rosane Moreira Santana, ${ }^{1}$ Marília Marques da Silva, ${ }^{2}$ Danielle Souza de Moraes, ${ }^{3}$ Cláudia Cristina Fukuda, $^{4}$
Lucia Helena Freitas, ${ }^{5}$ Maria Eveline Cascardo Ramos, ${ }^{6}$ Heloísa Junqueira Fleury, ${ }^{7}$ Chris Evans $^{8}$

\begin{abstract}
Introduction: The Clinical Outcome in Routine Evaluation Outcome Measurement (CORE-OM) was developed in the 1990s, with the aim of assessing the efficacy and effectiveness of mental health treatments.

Objective: To adapt the CORE-OM for use in the Brazilian population.

Method: The instrument was translated and adapted based on the international protocol developed by the CORE System Trust which contains seven steps: translation, semantic equivalence analysis, synthesis of the translated versions, pre-testing in the target population, data analysis and back translation.

Results: After semantic analysis, modifications were necessary in seven of the 34 original items. Changes were made to avoid repetition of words and the use of terms difficult to understand. Internal consistency analysis showed evidence of score stability in the CORE-OM adapted to Brazilian Portuguese. Conclusion: The instrument was successfully adapted to Brazilian Portuguese, and its semantic and conceptual properties were equivalent to those of the original instrument.

Keywords: CORE-OM, translation, instrument, assessment, psychotherapy.
\end{abstract}

\section{Resumo}

Introdução: O Clinical Outcome in Routine Evaluation - Outcome Measurement (CORE-OM) foi desenvolvido nos anos $1990 \mathrm{com}$ o objetivo de avaliar a eficácia e efetividade do tratamento em saúde mental.

Objetivo: Fazer a adaptação transcultural do instrumento CORE-OM para o português do Brasil.

Método: O modelo de tradução e adaptação foi baseado no protocolo internacional da equipe CORE System Trust, que compreende as sete etapas a seguir: tradução, avaliação da equivalência semântica, elaboração da versão síntese, aplicação na população, compilação dos dados e retrotradução.

Resultados: A partir da análise semântica, foram necessárias modificações em sete dos 34 itens originais. Foram feitas mudanças para evitar a repetição de termos assim como o uso de termos de difícil compreensão. A análise de consistência interna demonstrou evidência de estabilidade dos escores no CORE-OM adaptado.

Conclusão: $O$ instrumento foi adaptado para o português do Brasil, e as propriedades semânticas e conceituais dos itens resultantes foram equivalentes às do instrumento original.

Descritores: CORE-OM, tradução, instrumento, avaliação, psicoterapia.

\footnotetext{
${ }^{1}$ Psychologist. MSc in Medical Sciences: Psychiatry, Universidade Federal do Rio Grande do Sul (UFRGS), Porto Alegre, RS, Brazil. 2 Psychologist. PhD in Psychology, Universidade de Brasília (UNB), Brasília, DF, Brazil. Professor, Universidade Católica de Brasília (UCB), Brasília, DF, Brazil. ${ }^{3}$ Psychologist. MSc in Human Development, Centro Universitário La Salle (UNILASALLE), Canoas, RS, Brazil. ${ }^{4}$ Psychologist. PhD in Psychology, UNB, Brasília, DF, Brazil. Professor, Graduate Program in Psychology, UCB, Brasília, DF, Brazil. ${ }^{5}$ Psychiatrist. PhD in Clinical Medicine, UFRGS, Porto Alegre, RS, Brazil. Adjunct professor, Department of

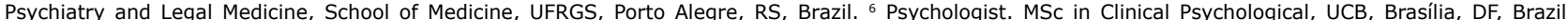
Professor, UCB, Brasília, DF, Brazil. 7 Psychologist. MSc in Sciences, School of Medicine, Universidade de São Paulo (USP), São Paulo, SP, Brazil. ${ }^{8}$ Psychologist. Professor and consultant medical psychotherapist, University of Nottingham and East London NHS Foundation Trust, London, UK.

Financial support: Fundo de Incentivo à Pesquisa - Hospital de Clínicas de Porto Alegre (FIPE-HCPA) and Universidade Católica de Brasília (UCB).

Submitted Jan 15 2015, accepted for publication Jun 02 2015. No conflicts of interest declared concerning the publication of this article.

Suggested citation: Santana MR, da Silva MM, de Moraes DS, Fukuda CC, Freitas LH, Ramos ME, et al. Brazilian Portuguese version of the CORE-OM: crosscultural adaptation of an instrument to assess the efficacy and effectiveness of psychotherapy. Trends Psychiatry Psychother. 2015;37(4):227-231. http://dx.doi. org/10.1590/2237-6089-2015-0002
} 


\section{Introduction}

Assessment of psychotherapeutic and psychosocial interventions has been extensively studied in mental health research and practice. The efficacy of such interventions has been scientifically proven by several studies, ${ }^{1,2}$ which have contributed to the systematization of this area of research, and helped bridge the gap between clinical practice and the teaching of psychotherapy. A focus on assessing the efficacy and effectiveness of therapeutic interventions is one product of current health care principles, which emphasize provision of comprehensive, universal and equitable care to all citizens. According to these principles, investigating the efficiency of health services such as psychotherapeutic and psychosocial care is an important tool for optimizing public health spending.

Assessment of psychotherapeutic interventions should include, among other methods, administration of standardized instruments to measure the progress of patients in therapy. Such instruments enable data to be collected that can be compared across individuals and cohorts. ${ }^{3,4}$

The present study describes the adaptation of the English version of the Clinical Outcomes in Routine Evaluation - Outcome Measure (CORE-OM) into Brazilian Portuguese. The version of the instrument produced as a result of this study will allow reliable data on the efficacy of psychotherapeutic interventions in Brazil to be collected. ${ }^{5}$

The CORE-OM was originally developed in the 1990s in the United Kingdom to serve as a standardized measure of the efficacy and effectiveness of psychotherapy. ${ }^{6-8} A$ search of the MEDLINE, LILACS and PubMed databases was conducted in an attempt to identify descriptions of use and adaptations of the CORE-OM, but no articles discussing adaptation of this instrument into Brazilian Portuguese were found. Although one article $^{9}$ was found describing adaptation of the instrument for use in Portugal, the present study is the first attempt to adapt the CORE-OM for use in Brazil.

A small number of instruments designed to assess factors that interact with or influence the psychotherapeutic process have been adapted into Brazilian Portuguese. ${ }^{10-14}$ Examples include the Brazilian version of the Psychotherapy Process Q-Set (PQS), developed by Serralta et al., ${ }^{15}$ which provides empirical and clinical descriptions of treatment progress in psychotherapies of different theoretical persuasions, and the Revised Conflict Tactics Scales (CTS2), ${ }^{14}$ which is used to assess the efficacy of couples therapy. However, these two instruments are highly specific in content, whereas the CORE-OM allows for an investigation of the efficacy of psychotherapy in general.
Several authors have raised concerns regarding the importance of preserving the original meaning of items in assessment instruments when these are adapted from one language to another. ${ }^{15}$ It is important to ensure conceptual and linguistic equivalence between the original instrument and its translated version. The semantic intention of the original instrument must also be preserved during the translation process, so as to assure the validity of the resulting instrument. ${ }^{8}$ As part of the adaptation process, literal translations of the assessment instruments must be submitted to careful analysis to ensure the adequacy of the words and terms to the cultural context and lifestyle of the target population. In the present study, the cross-cultural adaptation process was approved by CORE System Trust (www.coresystemtrust.org.uk/cst-translation-policy), as required for any translation of the CORE-OM, performed according to the steps outlined by Sales et al., ${ }^{9}$ and Reichenhem \& Moraes, ${ }^{14}$ and congruent with the excellent general guidelines in Wild et al., ${ }^{16}$ which include translation, an assessment of the semantic equivalence between the English and Portuguese versions of the CORE-OM, a synthesis between the translated versions of the instrument, back translation, pre-testing in the target population and internal consistency analysis.

\section{Method}

\section{Participants}

The semantic equivalence analysis was performed by community volunteers from the Federal District and the city of Porto Alegre, Brazil, as well as patients receiving psychotherapy at an outpatient trauma clinic in Porto Alegre. A total of 55 men and women aged $14-72$ years (mean $=37 \pm 17.4$ years) took part in the study. Participants were selected according to educational level. Table 1 presents distribution of participants by sex, city, group and educational level.

A second sample was recruited for pre-test study, which was conducted to collect evidence of internal consistency for the CORE-OM. This sample comprised 44 men and women, with different education level, patients of a psychology teaching clinic in the Federal District aged between 20 and 68 years $($ mean $=43.2 \pm 14.1$ years $)($ Table 1$)$.

\section{Instrument}

The CORE-OM is a self-report scale that was designed to be administered at the beginning and end of psychotherapy 
Table 1 - Distribution by gender, sample, city, and educational level, n (\%)

\begin{tabular}{lcc}
\hline Variable/category & Sample 1 (n = 55) & Sample 2 (n = 44) \\
\hline Gender & & $20(45.5)$ \\
Women & $24(43.6)$ & $24(54.5)$ \\
Men & $31(56.4)$ & $44(100)$ \\
Sample & & - \\
Clinical & $12(21.8)$ & \\
Non clinical & $43(78.2)$ & $44(100)$ \\
City & & - \\
Brasília & $26(47.3)$ & \\
Porto Alegre & $29(52.7)$ & $8(20.5)$ \\
Educational level & & $5(11.4)$ \\
Elementary (not completed) & $9(16.4)$ & $6(13.6)$ \\
Elementary & $7(12.7)$ & $11(25.0)$ \\
High school (not completed) & $8(14.5)$ & $8(18.2)$ \\
High school & $21(38.2)$ & $1(2.3)$ \\
Graduation & $7(12.7)$ & $5(11.4)$ \\
Post Graduation & $3(5.5)$ & - \\
Missing & - & \\
\hline
\end{tabular}

or at intervals within during longer-term therapy. It contains 34 items which assess the following four domains: subjective well-being (4 items); problems and symptoms (12 items); life functioning (12 items) and risk to self and others ( 6 items). These items are answered on a five-point scale, ranging from never to always or almost always. ${ }^{9}$

A study conducted in the United Kingdom with a clinical $(n=890)$ and a non-clinical sample $(n=1106)$ found an overall index of internal consistency (Cronbach's alpha) score of 0.94 for the two samples. Furthermore, test-retest correlations with part of the sample $(n=55)$ ranged from 0.87 to 0.91 for well-being, problems and symptoms, and life functioning domains, although the risk to self domain scored 0.64 , showing low temporal stability in this domain. Convergent validity was verified by correlating total scores and domain scores with overall scores from the Beck Depression Inventory (BDI), Beck Anxiety Inventory (BAI), Brief Symptom Inventory (BSI) and seven other scales, resulting in correlations ranging from 0.55 to $0.88 .^{7}$

\section{Procedure}

This study was approved by the Research Ethics Committees at the Hospital de Clínicas de Porto Alegre (CAAE: 057670120.0000.5327; protocol no. 293.943) and Universidade Católica de Brasília (CAAE: 08076112.3.0000.0029; protocol no. 149.790). The authors of the original instrument were contacted and gave permission for the CORE-OM to be adapted into
Brazilian Portuguese. The adaptation process employed was a slightly adapted (and approved) version of the CORE System Trust requirements for translations of CORE instruments and involved the following steps: translation, semantic equivalence analysis, synthesis of the translated versions, pre-testing in the target population, data analysis and back translation (Figure 1).

Two mental health professionals proficient in the English language independently translated the CORE-OM. The resulting translations were designated version 1 and version 2. These two documents were compared and discussed by the researchers, who combined them into a single document (version 3 ).

This version of the instrument was collectively administered to all participants involved in the semantic analysis of the scale, who were divided into groups of five after providing written consent to participation in the study. In the case of underage participants, consent was obtained from parents or legal guardians. The CORE-OM was then read out to participants, who were asked to explain their understanding of each of the items on the scale. Whenever responses differed between groups or from the meaning intended in the original text, participants were asked to discuss the item and suggest changes for clarity (focal groups). All suggestions were noted and analyzed by the researchers resulting in the final version, which was back translated into English once more and discussed with the last author (C.E.) of this article, who is one of the designers of the original, English language, instrument. 


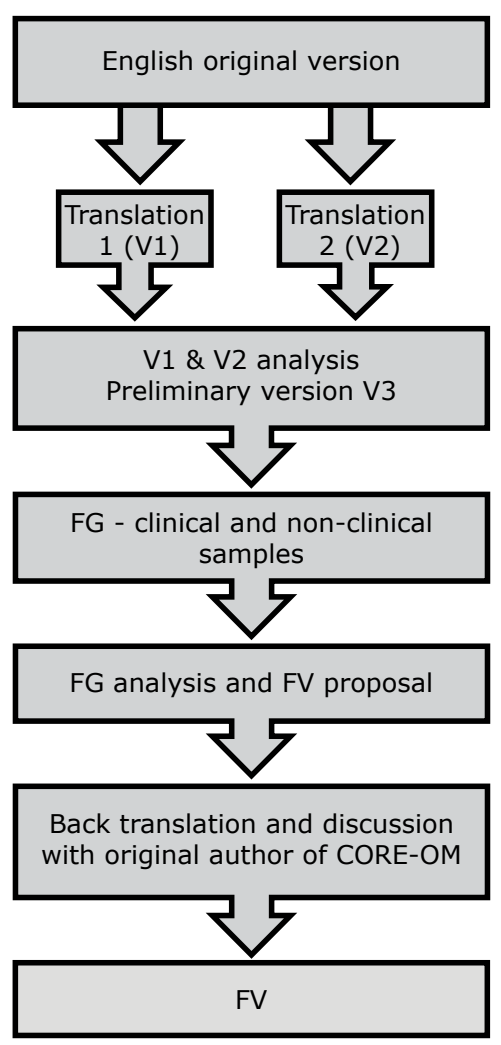

Figure 1 - Flowchart illustrating the process of adaptation to Brazil Portuguese of the Clinical Outcome in Routine Evaluation - Outcome Measurement (CORE-OM) semantic equivalence analysis. $F G=$ focal group; $F V=$ final version; $V=$ version.
In the pre-testing stage, psychology interns at a teaching clinic administered the CORE-OM to all patients who provided written consent to participation in the study. All patients seen at the clinic were invited to take part in the research. Seventy-five percent of respondents answered the questionnaire in the first six weeks of treatment, and no respondents were past the 13 th week of therapy.

\section{Results}

Comparison of the translations of the original CORE-OM into Brazilian Portuguese by two independent translators (versions 1 and 2) detected few differences. The differences found were analyzed by the Brazilian researchers who constructed version 3. Semantic analysis of version 3 resulted in modifications to seven items on the scale. Table 2 lists the changes suggested by participants during semantic analysis, all of which were incorporated in the final version of the scale.

The modifications included attempts to avoid the close repetition of words within items, such as item 3, "I have felt I have someone to turn to for support when needed," which was changed to "I have felt that, when necessary, I have someone to turn to for support." Difficulties in the comprehension of certain words were also observed. In item 15, for instance, the phrase

Table 2 - Comparison between original Clinical Outcome in Routine Evaluation - Outcome Measurement (CORE-OM) and versions 3 and 4 of Brazilian adaptation

\begin{tabular}{|c|c|c|c|}
\hline Item & Translation & Reason for change & Final version \\
\hline 3 & $\begin{array}{l}\text { I have felt I have someone } \\
\text { to turn to for support when } \\
\text { needed. }\end{array}$ & $\begin{array}{l}\text { Avoid keeping the words "have," in Portuguese } \\
\text { "tenho," close to each other. }\end{array}$ & $\begin{array}{l}\text { I have felt that, when necessary, I have } \\
\text { someone to turn to for support. }\end{array}$ \\
\hline 8 & $\begin{array}{l}\text { I have been troubled by } \\
\text { pains, suffering or other } \\
\text { physical problems. }\end{array}$ & $\begin{array}{l}\text { The word "suffering" was removed so that the item } \\
\text { would not be thought to refer to psychological } \\
\text { distress. }\end{array}$ & $\begin{array}{l}\text { I have been troubled by aches or other } \\
\text { physical problems. }\end{array}$ \\
\hline 11 & $\begin{array}{l}\text { Tension and anxiety have } \\
\text { left me unable to do } \\
\text { important things. }\end{array}$ & $\begin{array}{l}\text { The phrase "unable to" was replaced by "prevented } \\
\text { from," which is more commonly used in Brazilian } \\
\text { Portuguese. }\end{array}$ & $\begin{array}{l}\text { Tension and anxiety have prevented me } \\
\text { from doing important things. }\end{array}$ \\
\hline 15 & I have felt panic or terror. & $\begin{array}{l}\text { Respondents with low education levels had trouble } \\
\text { understanding the word "panic," and therefore, an } \\
\text { explanatory phrase was added in parentheses. }\end{array}$ & I have felt panic (intense fear) or terror. \\
\hline 19 & $\begin{array}{l}\text { I have felt care or affection } \\
\text { for someone. }\end{array}$ & $\begin{array}{l}\text { The sentence was ambiguous, with some } \\
\text { participants understanding it to mean that they } \\
\text { felt care and affection for someone, while others } \\
\text { interpreted it to mean that they felt cared for and } \\
\text { had affection towards someone. }\end{array}$ & $\begin{array}{l}\text { I feel I care and have affection for } \\
\text { someone. }\end{array}$ \\
\hline 23 & $\begin{array}{l}\text { I have felt desperate or } \\
\text { hopeless. }\end{array}$ & $\begin{array}{l}\text { The term "hopeless" was removed, since it did not } \\
\text { have the same meaning as "desperate." }\end{array}$ & I have felt desperate. \\
\hline 34 & $\begin{array}{l}\text { I have hurt myself } \\
\text { physically or taken } \\
\text { dangerous risks with my } \\
\text { health. }\end{array}$ & $\begin{array}{l}\text { The term "dangerous" was removed to avoid } \\
\text { redundancy with the word "risk." }\end{array}$ & $\begin{array}{l}\text { I have hurt myself physically or taken } \\
\text { risks with my health. }\end{array}$ \\
\hline
\end{tabular}


"intense fear" was added following the term "panic," while in item 11, the phrase "unable to" was changed to "prevented from" (item 11).

In item 8, some participants understood the term "suffering" to refer to psychological distress, whereas in the original version of the instrument this item refers to physical suffering only. Therefore, this term was removed from the scale. The ambiguity in the sentence "I feel care and affection for someone" was addressed by changing this item to "I feel I care and have affection for someone" (item 19).

Item 3 was the most difficult for participants to comprehend and 3 questions, were asked about their meaning. However, no changes were proposed to these items. Items 11 and 19 received the greatest number of suggested modifications.

At the end of this stage, researchers incorporated the modifications suggested by participants into version 3 , which resulted in the final version of the scale. The final version was back-translated by another English-speaking professional who was unfamiliar with the original instrument. The resulting document was checked with C.E. and all amendments approved as good examples of semantic adaptation.

The final version was then administered to the second sample of participants to allow for analysis of its internal consistency. The Cronbach's alpha for this version of the scale was 0.90 , demonstrating adequate internal consistency and not statistically significantly different from the value of $0.94 .^{7}$

\section{Conclusion}

Cross-cultural adaptation of the CORE-OM for Brazilian Portuguese was conducted following steps proposed by the original author ${ }^{3}$ as well as in other studies in the literature. ${ }^{4}$ Comprehensibility of the translation for the target population was ensured by semantic analysis, and by incorporation of participants' suggestions into the scale.

The objective of this study was achieved, and the CORE-OM was successfully adapted for Brazilian Portuguese. The final version of the instrument could be understood by participants with different education levels, ages and cultural backgrounds, since the instrument was administered to people from two Brazilian cities in different regions of the country. Preliminary data on the internal consistency of the CORE-OM suggested that the instrument has adequate psychometric properties. However, further studies still need to be conducted to confirm the validity and reliability of the Brazilian Portuguese version of the CORE-OM that was developed in this study.

\section{References}

1. Straub RO. Psicologia da saúde. Porto Alegre: Artmed; 2005.

2. Peuker AC, Habigzang LF, Koller SH, Araújo LB. Avaliação de processo e resultado em psicoterapias: uma revisão. Psicol Estud. 2009; 14:439-45.

3. Nunes MLT, Lhullier AC. Histórico da pesquisa empírica em psicoterapia. Rev Bras Psicoter. 2003;5:97-112.

4. Del Prette ZAP, Del Prette A. Significância clínica e mudança confiável na avaliação de intervenções psicológicas. Psic Teor Pesq. 2008;24:497-505.

5. Bortoncello CF, Vivian A, Gomes JB, Cordioli AV. Translation and adaptation into Brazilian Portuguese of the Obsessional Beliefs Questionnaire (OBQ-44). Trends Psychiatry Psychother. 2012;34:31-7.

6. Evans C, Mellor-Clark J, Margison F, Barkham M, Audin K, Connell J, et al. CORE: Clinical Outcomes in Routine Evaluation. J Ment Health. 2000;9:247-55.

7. Evans C, Connell J, Barkham M, Margison F, McGrath G, Mellor-Clark J, et al. Towards a standardised brief outcome measure: psychometric properties and utility of the CORE-OM. Br J Psychiatry. 2002;180:51-60.

8. Evans C. The CORE-OM (Clinical Outcomes in Routine Evaluation) and its derivatives. Int Sci Pract. 2012;2:12-5.

9. Sales CMD, Moleiro CMM, Evans C, Alves PCG. Versão Portuguesa do CORE-OM: tradução, adaptação e estudo preliminar das suas propriedades psicométricas. Rev Psiquiatr Clin. 2012;39:54-9.

10. Mattos $P$, Segenreich D, Saboya E, Louzã M, Dias G, Romano M. Adaptação transcultural para o português da escala Adult Self-Report Scale para avaliação do transtorno de déficit de atenção/hiperatividade (TDAH) em adultos. Rev Psiquiatr Clin. 2006;33:188-94.

11. Portilho-Souza E, Nina e Silva CH. Tradução e adaptação da escala bis/bas para aplicação em adultos brasileiros. Rev UninCor. 2013;11:470-6.

12. Lino VT, Pereira SR, Camacho LA, Ribeiro Filho ST, Buksman S. [Cross-cultural adaptation of the Independence in Activities of Daily Living Index (Katz Index)]. Cad Saude Publica. 2008;24:103-12.

13. Serralta FB, Nunes MLT, Eizirik CL. Elaboração da versão em português do Psychotherapy Process Q-Set. Rev Psiquiatr Rio Gd Sul. 2007;29:44-55.

14. Reichenhem ME, Moraes CL. [Operationalizing the cross-cultural adaptation of epidemiological measurement instruments]. Rev Saude Publica. 2007;41:665-73.

15. Streiner DL, Norman GR. Health measurements scales: a pratical guide to their development and use. New York: Oxford University; 1995.

16. Wild D, Grove A, Martin M, Eremenco S, McElroy S, Verjee-Lorenz A, et al. Principles of good practice for the translation and cultural adaptation process for Patient-Reported Outcomes (PRO) measures: report of the ISPOR task force for translation and cultural adaptation. Value Health. 2005;8:94-104.

\section{Correspondence:}

Márcia Rosane Moreira Santana

Rua Dona Augusta, 427/304, Menino Deus

CEP 90850-130 - Porto Alegre, RS - Brazil

Tel.: +55 (51) 8456-2724

E-mail: marciasantana1@yahoo.com.br 